\title{
Greater palatine foramen - key to successful hemimaxillary anaesthesia: a morphometric study and report of a rare aberration
}

\author{
Namita Alok Sharma ${ }^{1}$, MD, Rajendra Somnath Garud², MD
}

INTRODUCTION Accurate localisation of the greater palatine foramen (GPF) is imperative while negotiating the greater palatine canal for blocking the maxillary nerve within the pterygopalatine fossa. The aim of this study was to define the position of the foramen relative to readily identifiable intraoral reference points in order to help clinicians judge the position of the GPF in a consistently reliable manner.

METHODS The GPF was studied in 100 dried, adult, unsexed skulls from the state of Maharashtra in western India. Measurements were made using a vernier calliper.

RESULTS The mean distances of the GPF from the midline maxillary suture, incisive fossa, posterior palatal border and pterygoid hamulus were $14.49 \mathrm{~mm}, 35.50 \mathrm{~mm}, 3.40 \mathrm{~mm}$ and $11.78 \mathrm{~mm}$, respectively. The foramen was opposite the third maxillary molar in $73.38 \%$ of skulls, and the direction in which the foramen opened into the oral cavity was found to be most frequently anteromedial (49.49\%). In one skull, the greater and lesser palatine foramina were bilaterally absent. Except for the invariably present incisive canals, there were no accessory palatal foramina, which might have permitted passage of the greater palatine neurovascular bundle in lieu of the absent GPF. To the best of our knowledge, this is the first study of such a non-syndromic presentation.

CONCLUSION The GPF is most frequently palatal to the third maxillary molar. For an edentulous patient, the foramen may be located 14-15 mm from the mid-palatal raphe or about $12 \mathrm{~mm}$ anterior to the palpable pterygoid hamulus.

Keywords: greater palatine canal, greater palatine foramen, hard palate, maxillary nerve block, pterygopalatine fossa

\section{INTRODUCTION}

The maxillary division of the trigeminal nerve is wholly sensory and leaves the skull via the foramen rotundum, which opens directly into the posterior wall of the pterygopalatine fossa (PPF). The three main branches of the maxillary nerve, as it crosses the upper part of the fossa, are the anterior (formerly the greater) palatine nerve, the zygomatic nerve and the infraorbital nerve. ${ }^{(1)}$

The sensory supply of the palate is exclusively via the maxillary nerve. The principal branch that supplies the palate is the anterior palatine nerve, which descends through the greater palatine canal (GPC), emerges on the hard palate at the greater palatine foramen (GPF) and runs forward in a groove almost up to the incisor teeth where it communicates with the terminal filaments of the nasopalatine nerve. This latter nerve, which is also a branch of the maxillary nerve, enters the palate at the incisive foramen and supplies the anterior part of the hard palate behind the incisor teeth. ${ }^{(2)}$ The boundary between the areas innervated by the two nerves corresponds roughly to a line drawn between the maxillary canines, although the two areas are not as sharply delineated as such an imaginary line might suggest. ${ }^{(3)}$ By severing the nasopalatine nerve, Langford showed that the anterior palatine nerve may play a larger role in the innervation of the anterior palate than had previously been thought. ${ }^{(4)}$ The middle and posterior (lesser) palatine nerves diverge from the GPC and emerge through the lesser palatine foramina (LPF) to supply the uvula, tonsil and soft palate.(2)

Blocking sensation of the maxillary nerve in the PPF achieves anaesthesia of the maxillary teeth, the maxillary palatal and gingival tissue, as well as the skin of the midface, nasal cavity and sinus. ${ }^{(5)}$ Such a maxillary block would be necessary prior to various surgical procedures in this region, in patients with maxillary trauma, and for the diagnosis and treatment of chronic oral and maxillofacial pain syndromes. ${ }^{(6)}$ Furthermore, as a simple infiltration into the buccal sulcus, adjacent to the tooth to be worked on, may be contraindicated in patients with an infection in the region, dentists may also need to resort to maxillary nerve blocks.

There are two intraoral approaches to the maxillary nerve - the high tuberosity approach and the GPC approach. In the former, the needle inserted into the buccal sulcus is directed superiorly, medially and posteriorly along the infratemporal surface of the maxilla to enter the PPF. Complications of this approach include a lack of profound anaesthesia and a relatively high risk of haematoma due to the proximity of the pterygoid venous plexus. ${ }^{(1)}$ In the GPC approach, the needle is inserted through the GPF and advanced till it reaches the inferior part

${ }^{1}$ Department of Anatomy, Bharati Vidyapeeth Deemed University, Dental College and Hospital, ${ }^{2}$ Department of Anatomy, Bharati Vidyapeeth Deemed University, Medical College and Hospital, Pune, India

Correspondence: Dr Namita Sharma, Assistant Professor, Department of Anatomy, Bharati Vidyapeeth Deemed University, Dental College and Hospital, Dhanakwadi, Pune 411043, India. drnamitaalok@gmail.com 
Table I. Intraobserver analysis for all measurements.

\begin{tabular}{lcc}
\hline Parameter & \multicolumn{2}{c}{ Intraclass correlation value (95\% Cl) } \\
\cline { 2 - 3 } & Right & Left \\
\hline Anteroposterior dimension of GPF & $0.9897(0.9847-0.9931)$ & $0.9917(0.9876-0.9944)$ \\
Distance between GPF and midline maxillary suture & $0.9984(0.9976-0.9989)$ & $0.9980(0.9971-0.9987)$ \\
Distance between GPF and incisive fossa & $0.9964(0.9946-0.9976)$ & $0.9909(0.9859-0.9941)$ \\
Distance between GPF and posterior palatal border & $0.9958(0.9936-0.9973)$ & $0.9918(0.9839-0.9958)$ \\
Distance between GPF and pterygoid hamulus & $0.9937(0.9876-0.9968)$ & $0.9977(0.9965-0.9985)$ \\
Distance from the infraorbital foramen to the alveolar & $0.9977(0.9964-0.9985)$ & \\
crest between the maxillary bicuspids & & \\
\hline
\end{tabular}

$\mathrm{Cl}$ : confidence interval; GPF: greater palatine foramen

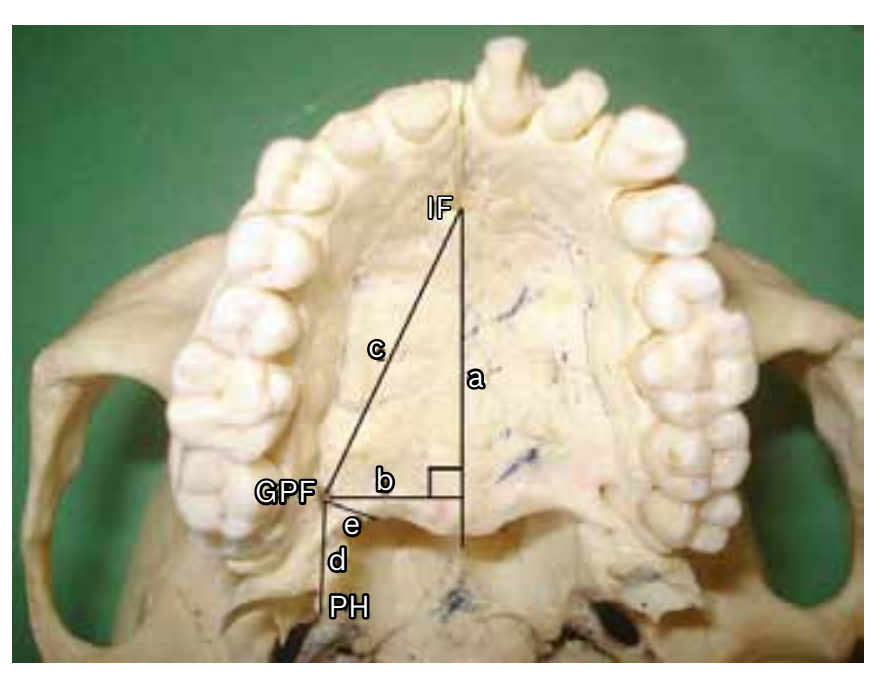

Fig. 1 Photograph shows the fixed intraoral anatomical reference points for calculating their distances from the greater palatine foramen.

GPF: greater palatine foramen; IF: incisive fossa; $\mathrm{PH}$ : pterygoid hamulus; $a$ : midline maxillary suture; $b$ : perpendicular distance from GPF to midline maxillary suture; $c$ : distance from GPF to IF; d: distance from GPF to PH; e: distance from GPF to the posterior palatal border (point of maximum concavity)

of the PPF, where the anaesthetic is deposited. ${ }^{(5)}$ This method of obtaining a maxillary block has a high success rate ( 95\%) with minimal risk. ${ }^{(7)}$ A further advantage of this approach is the fact that the needle traverses the shortest route of any technique to block the maxillary nerve. ${ }^{(6)}$

However, apart from being contraindicated in patients with an infection or inflammation in the region of the GPF, there are certain anatomical constraints that need be considered while adopting the GPC approach. This includes the difficulty in locating the GPF, as it is covered by the palatal mucosa. Though rare, an anterolaterally directed GPF - as seen in $38.7 \%$ of Nigerian skulls $^{(8)}$ - would be difficult to negotiate. Likewise, tortuosity of the canal, as observed in 5\% of the population studied by Hawkins and Isen, ${ }^{(1)}$ as well as a relatively horizontal course of the canal with respect to the palatal anatomy, as noted in $18 \%$ of skulls studied by Westmoreland and Blanton, ${ }^{(9)}$ would both impede the passage of the needle.

The purpose of this study was to define the position of the GPF in relation to certain fixed intraoral anatomical reference points, all of which would either be visible or palpable in the living patient. This would aid clinicians in locating the foramen in a consistently reliable manner. The observations made in the present study were compared with those of earlier studies on skulls belonging to either the same or different races. Ethnicity as a cause of variation is also discussed.

\section{METHODS}

The study was conducted on a convenience sample of 100 dried, adult, unsexed Indian skulls from the state of Maharashtra in western India. The skulls, obtained from the museums of the medical and dental colleges in Pune, were all in good condition and free from any obvious pathology. Of the skulls studied, 17 were edentulous. Among the remaining skulls, 13 right-sided and 12 left-sided third maxillary molars had not erupted. The adult status of these latter skulls was established on the basis of the fused basiocciput and basisphenoid, as seen on the cranial base.

Fixed intraoral reference points were identified and the distances of the GPF from these points were noted (Fig. 1). These reference points included the perpendicular distance from the medial edge of the foramen to the midline maxillary suture, distance from the anterior edge of the foramen to the incisive fossa and distances from the posterior edge of the foramen to the point of maximum concavity of the posterior palatal border and the pterygoid hamulus. Apart from this, the distance between the infraorbital foramen (IOF) and the alveolar crest between the maxillary bicuspids was measured, as it is a reliable indicator of the length of the GPC and would thus help in judging the depth to which the needle should penetrate in order to reach the PPF through the GPF. Other metrical data included the sagittal dimensions of the GPF.

Measurements were made using a vernier calliper with a range of $0-300 \mathrm{~mm}$ and a fine adjustment carriage with a least count of $0.02 \mathrm{~mm}$. Each measurement was taken twice by the same observer, and in cases with any discrepancy, the mean of the two values was recorded. For the purpose of identification, the skulls were numbered and the two sets of readings (right and left) were taken on successive days. To eliminate observer bias, the first set of values was not referred to while recording the second set of measurements. Comparison of the results of the right and left measurements revealed that intraclass correlation coefficient values were all greater than 0.9 (Table I), indicating 
Table II. Measurements of the greater palatine foramen (GPF) with respect to selected intraoral reference points.

\begin{tabular}{|c|c|c|c|c|}
\hline \multirow[t]{2}{*}{ Parameter } & \multicolumn{3}{|c|}{ Distance $(\mathrm{mm})$} & \multirow[t]{2}{*}{ p-value } \\
\hline & Right & Left & Total & \\
\hline GPF to midline maxillary suture & $14.71 \pm 1.38(12.00-17.90)$ & $14.41 \pm 1.39(11.20-17.68)$ & $14.49 \pm 1.79$ & 0.115 \\
\hline GPF to incisive fossa & $35.42 \pm 2.75(29.90-43.20)$ & $35.66 \pm 2.61(29.60-43.20)$ & $35.50 \pm 2.59$ & 0.23 \\
\hline GPF to posterior palatal border & $3.42 \pm 1.45(0.80-10.60)$ & $3.38 \pm 1.49(1.18-12.40)$ & $3.40 \pm 1.47$ & 0.51 \\
\hline GPF to pterygoid hamulus & $12.12 \pm 2.53(6.70-18.20)$ & $11.47 \pm 1.90(7.12-16.40)$ & $11.78 \pm 2.23$ & $0.0019^{*}$ \\
\hline $\begin{array}{l}\text { Infraorbital foramen to the alveolar } \\
\text { crest between the maxillary bicuspids }\end{array}$ & $29.01 \pm 3.17(20.90-37.00)$ & $29.43 \pm 3.25(20.90-37.66)$ & $29.22 \pm 3.21$ & $0.039^{*}$ \\
\hline Anteroposterior diameter of GPF & $4.67 \pm 1.13(1.90-14.94)$ & $4.88 \pm 1.58(1.68-14.40)$ & $4.72 \pm 1.40$ & 0.266 \\
\hline
\end{tabular}

Data is presented as mean \pm standard deviation (range). ${ }^{*} p<0.05$ was considered statistically significant.

Table III. The greater palatine foramen in relation to the maxillary molars in skulls with erupted third molars.

\begin{tabular}{lccc}
\hline Relation & \multicolumn{3}{c}{ No. (\%) } \\
\cline { 2 - 4 } & $\begin{array}{c}\text { Right } \\
(\mathbf{n}=\mathbf{6 9})\end{array}$ & $\begin{array}{c}\text { Left } \\
\mathbf{( n = 7 0 )}\end{array}$ & $\begin{array}{c}\text { Total } \\
(\mathbf{n}=\mathbf{1 3 9})\end{array}$ \\
\hline $\begin{array}{l}\text { Anterior half of second } \\
\text { molar }\end{array}$ & $0(0)$ & $1(1.43)$ & $1(0.72)$ \\
$\begin{array}{l}\text { Posterior half of second } \\
\text { molar }\end{array}$ & $6(8.70)$ & $5(7.14)$ & $11(7.91)$ \\
$\begin{array}{l}\text { Anterior half of third } \\
\text { molar }\end{array}$ & $23(33.33)$ & $26(37.14)$ & $49(35.25)$ \\
$\begin{array}{l}\text { Posterior half of third } \\
\text { molar }\end{array}$ & $25(36.23)$ & $28(40)$ & $53(38.13)$ \\
Distal to third molar & $15(21.74)$ & $10(14.29)$ & $25(17.99)$ \\
\hline
\end{tabular}

a very high level of agreement between the two sets of readings taken.

Other parameters under which the GPF was studied included the relation of the foramen to the maxillary molars, the direction of the palatal opening of the foramen, the patency of the GPC to a 26-gauge needle and the number of LPF. At times, a bony projection along the posterior border of the GPF (akin to the lingula of the mandibular foramen) was present, in which case the frequency of its occurrence was noted. The presence of this inconsistent anatomic feature could prove to be a useful parameter, as it could offer a bony barrier to the needle slipping posteriorly and injuring the soft palate.

To determine the direction of the GPF, a 26-gauge needle was inserted into the canal while holding the skull such that the oral surface of the hard palate was face-upward and parallel to the horizontal plane (Frankfurt plane) passing from the inferior margin of the bony orbit to the superior margin of the external acoustic meatus. The direction of the canal was classified as anteromedial if the needle was directed toward the maxillary incisors, and anterolateral if the needle was directed toward the ipsilateral maxillary molars. A needle position intermediate to the above two was taken to indicate an anteriorly directed canal. The other direction noted was the foramen directed vertically inferior.

All linear measurements were recorded in millimetres and a comparison between all right and left measurements was done using the paired $t$-test. The differences between the groups were considered significant if $\mathrm{p}<0.05$.

\section{RESULTS}

The GPF was bilaterally absent in one of the 100 skulls studied. Therefore, the distances of the GPF from the selected intraoral reference points were measured using a vernier calliper for 99 of the 100 skulls studied (excluding the skull where the GPF was absent). The measurements of the GPF in relation to the selected intraoral reference points are presented in Table II. Statistical analysis indicated no significant difference in the measurements between the right and left sides for the distance from GPF to midline maxillary suture $(p=0.115)$, distance from GPF to incisive fossa $(p=0.23)$, and distance from GPF to posterior palatal border $(p=0.51)$. However, the difference between the two sides was found to be significant for the distance measured between the foramen and the pterygoid hamulus ( $p=0.0019$ ), as well as that between the IOF and the alveolar crest between the two maxillary bicuspids ( $p=0.039$ ).

Of the 99 skulls in which the GPF was present, 17 were edentulous. Among the remaining 82 skulls, the third maxillary molar had not erupted in 12 skulls bilaterally and in one skull unilaterally (on the right side). Thus, for 34 foramina in these skulls, its relationship with the molars could not be defined. For 25 foramina related to dentulous maxillae where only the corresponding third maxillary molar was absent, the GPF was seen to be distal to the second molar in $84 \%$ of the foramina examined and opposite the posterior half of the second molar in the remaining $16 \%$ of foramina. Of the remaining 139 foramina associated with a complete complement of maxillary teeth, the GPF was most frequently seen to be opposite $(73.38 \%)$ or distal $(17.99 \%)$ to the third molar. Only in $8.63 \%$ of cases were the foramina opposite the second molar (Table III). Table IV shows the intraoral direction of the GPF, which was most often noted to be either anteromedial (49.49\%) or vertically inferior (44.95\%). An anterolateral direction of the foramen was seldom seen (3.54\%). A lingular bony projection on the posterior edge of the GPF was observed in $27.77 \%$ of the foramina studied, while the canal was patent to a 26 -gauge needle in $95.96 \%$ of foramina (Table V).

Although the anteroposterior (greatest) dimensions of the GPF were found to vary over a very wide range of values in our study, the difference between the two sides of a skull was not significant ( $p=0.266$, Table II). The mean number of LPF observed was 1.39 and 1.43 for the right and left sides, respectively (ranging from 0 to a maximum of 5). In 54\% of the 100 skulls 
Table IV. Intraoral direction of the greater palatine foramen.

\begin{tabular}{lccc}
\hline Direction & \multicolumn{3}{c}{ No. (\%) } \\
\cline { 2 - 4 } & $\begin{array}{c}\text { Right } \\
(\mathbf{n}=\mathbf{9 9 )}\end{array}$ & $\begin{array}{c}\text { Left } \\
(\mathbf{n}=\mathbf{9 9})\end{array}$ & $\begin{array}{c}\text { Total } \\
(\mathbf{n}=\mathbf{1 9 8})\end{array}$ \\
\hline Vertically inferior & $44(44.40)$ & $45(45.45)$ & $89(44.95)$ \\
Anteriorly & $2(2.02)$ & $2(2.02)$ & $4(2.02)$ \\
Anteromedial & $49(49.49)$ & $49(49.49)$ & $98(49.49)$ \\
Anterolateral & $4(4.04)$ & $3(3.03)$ & $7(3.54)$ \\
\hline
\end{tabular}

Table V. Presence of a lingular bony projection from the posterior border of the greater palatine foramen and patency of the greater palatine canal.

\begin{tabular}{lccc}
\hline Parameter & \multicolumn{3}{c}{ No. (\%) } \\
\cline { 2 - 4 } & $\begin{array}{c}\text { Right } \\
(\mathbf{n}=\mathbf{9 9 )}\end{array}$ & $\begin{array}{c}\text { Left } \\
(\mathbf{n}=\mathbf{9 9 )}\end{array}$ & $\begin{array}{c}\text { Total } \\
(\mathbf{n}=\mathbf{1 9 8})\end{array}$ \\
\hline $\begin{array}{l}\text { Presence of a lingular } \\
\text { bony projection }\end{array}$ & $32(32.32)$ & $23(23.23)$ & $55(27.77)$ \\
$\begin{array}{l}\text { Patency to 26-gauge } \\
\text { needle }\end{array}$ & $96(96.97)$ & $94(94.95)$ & $190(95.96)$ \\
\hline
\end{tabular}

studied, there was bilateral symmetry in the number of LPF seen. Bilateral absence of the LPF was seen in two skulls, while unilateral absence of the LPF was noted on the right and left sides in five and seven skulls, respectively.

In one skull, there were multiple anomalies including complete bilateral absence of the GPF and LPF (Fig. 2). Shallow sulci along the lateral edges of the hard palate, as are normally produced by the greater palatine neurovascular bundle, were present in this skull. There was also fusion of the pterygoid plates with the body of the maxilla bilaterally, resulting in closure of both the pterygomaxillary fissures (Fig. 3). However, communication between the PPF and infratemporal region was possible through the inferior orbital fissure. There was bilateral absence of both the vomerovaginal and palatovaginal canals (Fig. 2). Interestingly, this skull had other anomalies as well, including bilateral absence of the carotid canals. The two foramen lacerum were impressively circular and smooth edged.

\section{DISCUSSION}

The greater palatine neurovascular bundle gains an intraoral entry through the GPF, which thus merits caution during any palatal surgery. Excessive resistance while trying to negotiate the GPC could well be a consequence of the inability of the clinician to accurately locate the GPF. On the other hand, a common error observed while attempting the GPC approach to the maxillary nerve is the needle stepping off the posterior aspect of the hard palate, in which case, the anaesthetic would be deposited in the nasopharynx. ${ }^{(10)}$ Clinicians should suspect the latter if there is a complete lack of resistance to the advancing needle. It is thus imperative that the position of the foramen be defined relative to intraoral reference points, which are readily identifiable in a living patient.

In our study, the mean distance of the GPF from the midline maxillary suture fell well within previously established averages

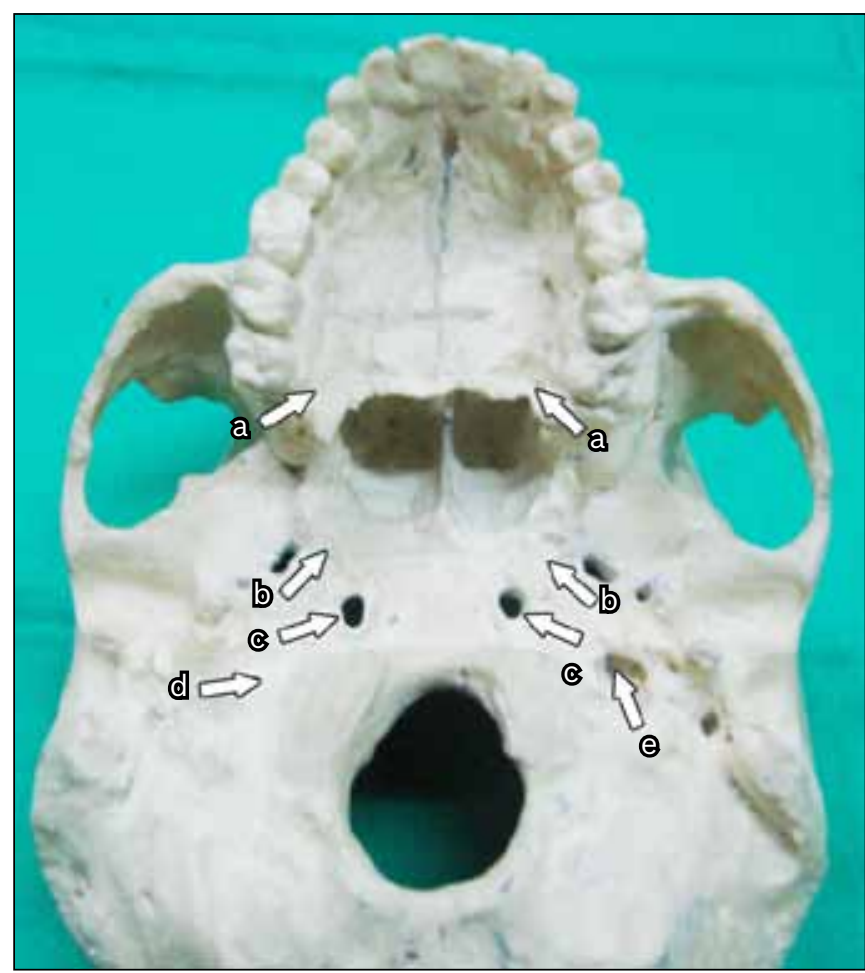

Fig. 2 Photograph of the base of the skull shows bilateral absence of the greater and lesser palatine foramina (a) as well as bilateral absence of the vomerovaginal and palatovaginal canals (b). Smooth rounded foramina lacerum (c), complete absence of the right-sided carotid canal (d), and a blind fossa in lieu of the left-sided carotid canal (e) are also seen.

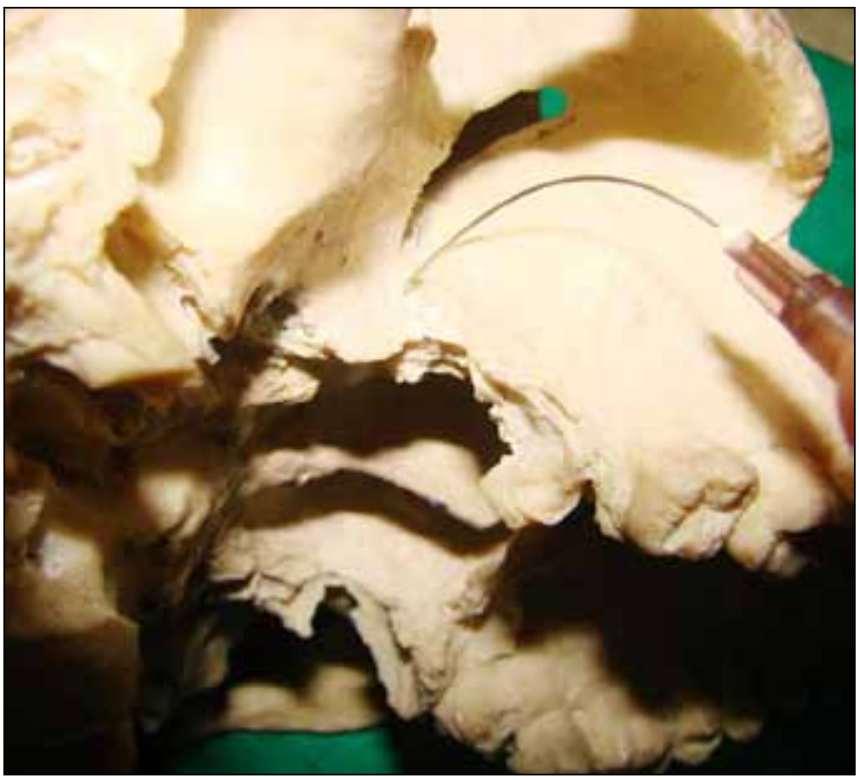

Fig. 3 Photograph shows the bent needle, indicating absence of the pterygomaxillary fissure due to fusion of the pterygoid plates with the body of the maxilla in the skull, with complete bilateral absence of the greater and lesser palatine foramina.

(Table VI). ${ }^{(6,8-14)}$ The mean value for this measurement in the present study was in agreement with those of earlier studies on Indian skulls. ${ }^{(8,11)}$ The authors are therefore of the opinion that globally, the foramen might be consistently located 14-15 mm from the mid-palatine raphe.

However, the mean distance of the GPF from the posterior palatal border was highly variable in our study (Table VI). While Westmoreland and Blanton ${ }^{(9)}$ documented an average distance 
Table VI. Comparison of data from the literature on the mean distance of the GPF from the midline maxillary suture and posterior palatal border.

\begin{tabular}{|c|c|c|}
\hline \multirow[t]{2}{*}{ Study } & \multicolumn{2}{|c|}{ Mean distance $(\mathrm{mm})$} \\
\hline & GPF to midline maxillary suture & GPF to posterior palatal border \\
\hline Methathrathip et al ${ }^{(6)}$ & 16.20 & 5.10 \\
\hline \multicolumn{3}{|l|}{ Ajmani $^{(8)}$} \\
\hline Indian skulls & $14.70(\mathrm{R}), 14.6 \mathrm{O}(\mathrm{L})$ & $3.70(\mathrm{R}), 3.70(\mathrm{~L})$ \\
\hline Nigerian skulls & $15.40(R), 15.40(L)$ & $3.50(R), 3.50(L)$ \\
\hline Westmoreland and Blanton ${ }^{(9)}$ & $14.80(\mathrm{R}), 15(\mathrm{~L})$ & 1.90 \\
\hline Malamed and Treiger ${ }^{(10)}$ & - & 6.97 \\
\hline Saralaya and Nayak $k^{(11)}$ & 14.70 & 4.20 \\
\hline Wang et $\mathrm{al}^{(12)}$ & 16 & 4.11 \\
\hline Klosek and Rungruang ${ }^{(13)}$ & 14.70 & - \\
\hline Chrcanovic and Custódio(14) & $14.68(R), 14.44(L)$ & 3.39 \\
\hline Present study & $14.71(\mathrm{R}), 14.41(\mathrm{~L})$ & $3.42(\mathrm{R}), 3.38(\mathrm{~L})$ \\
\hline
\end{tabular}

GPF: greater palatine foramen; L: left; R: right

Table VII. Comparison of data from the literature on the positional variance of the GPF with respect to the maxillary molars.

\begin{tabular}{|c|c|c|c|c|}
\hline \multirow[t]{2}{*}{ Study } & \multicolumn{4}{|c|}{ Position of GPF (\%) } \\
\hline & Opposite 2nd molar & Between 2nd and 3rd molar & Opposite 3rd molar & Distal to 3rd molar \\
\hline Methathrathip et al ${ }^{(6)}$ & 5.60 & 23.10 & 64.40 & 6.90 \\
\hline \multicolumn{5}{|l|}{ Ajmani ${ }^{(8)}$} \\
\hline Indian skulls & - & 32.35 & 64.69 & 2.94 \\
\hline Nigerian skulls & 13.07 & 38.46 & 48.46 & 0 \\
\hline Malamed and Treiger ${ }^{(10)}$ & 39.87 & - & 60.12 & - \\
\hline Saralaya and Nayak $k^{(11)}$ & 0.40 & 24.20 & 74.60 & 0.80 \\
\hline Wang et $\mathrm{al}^{(12)}$ & 17 & 48 & 33.50 & - \\
\hline Chrcanovic and Custódio ${ }^{(14)}$ & 0 & 6.91 & 54.80 & 38.94 \\
\hline Sujatha et al(15) & 0.88 & 13.15 & 85.95 & - \\
\hline Hassanali and Mwaniki ${ }^{(16)}$ & 10.40 & 13.60 & 76 & - \\
\hline Present study & 8.63 & 0 & 73.38 & 17.99 \\
\hline
\end{tabular}

GPF: greater palatine foramen

of $1.9 \mathrm{~mm}$, Malamed and Trieger, ${ }^{(10)}$ who conducted their study on ethnically diverse groups (including those from western United States, Scandinavia, Europe and North Africa), found the mean to be $6.97 \mathrm{~mm}$ (range 3-12 $\mathrm{mm}$ ). The corresponding mean values in the present study were $3.42 \mathrm{~mm}$ and $3.38 \mathrm{~mm}$ on the right and left sides, respectively. Interestingly, despite such discrepancy, our results were comparable to that of Ajmani's study on the Indian population ${ }^{(8)}$ (Table VI). According to Hawkins and Isen, however, the foramen could be located about $7 \mathrm{~mm}$ anterior to the posterior palatal border (range 1.8-12 mm). ${ }^{(1)}$ Given the disparity in the reported values of this parameter among various studies (Table VI), the authors inferred that no conclusive figure could be advocated for this distance. In Indian skulls, nevertheless, the foramen would most likely lie 3-4 mm anterior to the posterior palatal border.

The pterygoid hamulus bears a consistent relationship to the GPF in the sagittal plane. Hawkins and Isen have described the location of the foramen to be along an imaginary line from this process to the ipsilateral cingulum of the lateral incisor. ${ }^{(1)}$ In our study, the mean distance between the foramen and the tip of the hamulus $(11.78 \mathrm{~mm}$ ) was comparable to the findings of
Malamed and Trieger $(12 \mathrm{~mm}) .{ }^{(10)}$ Therefore, the authors maintain that it is possible to gainfully employ the palpable hamulus for accurate location of the foramen.

All studies, except that by Wang et al, ${ }^{(12)}$ have consistently found that the GPF is most frequently opposite the third molar (Table VII), ${ }^{(6,8,10-12,14-16)}$ which would thus seem to be a reliable landmark when attempting to locate the foramen. Nevertheless, there are some differences seen among the various studies. It is interesting to note that in the transethnic study conducted by Malamed and Treiger, nearly $40 \%$ of the foramina were found opposite the second molar as opposed to other studies that only documented very low values for such a position of the GPF.(10) Inconsistency is evident even among various Indian studies. We found the foramen to be distal to the third molar in $17.99 \%$ of the skulls studied. This incidence is far higher than the findings of Ajmani (in his study of Indian skulls), ${ }_{,}^{(8)}$ Saralaya and Nayak, ${ }^{(11)}$ and Sujatha et al. ${ }^{(15)}$

Klosek and Rungruang studied the topography of the palate with special reference to obtaining free gingival and connective tissue grafts from this area in order to correct alveolar/gingival mucosal deformities. ${ }^{(13)}$ To estimate the possible length of the 
graft, the linear measurement of the alveolar process of the maxilla, along which the greater palatine artery runs, needs to be assessed, and this can be used to estimate the distance of the GPF from the incisive fossa. In our study, the mean value for this measurement was $35.5 \mathrm{~mm}$, which is comparable to previous reports by Saralaya and Nayak (37.3 mm), ${ }^{(11)}$ Klosek and Rungruang (34 mm), ${ }^{(13)}$ and Chrcanovic and Custódio (right side $36.2 \mathrm{~mm}$, left side $36.5 \mathrm{~mm}) .{ }^{14}$

Various researchers have studied the direction of the GPF as it opens onto the palate, and the results documented have varied widely. In the present study, the percentage of skulls with the foramen opening vertically inferior and anteromedially were $44.95 \%$ and $49.49 \%$, respectively. Ajmani's study on Indian skulls found $91.4 \%$ of the foramina to be directed anteromedially, ${ }^{(8)}$ while the majority of foramina ( $82 \%$ ) studied by Westmoreland and Blanton were directed vertically inferior. ${ }^{(9)}$ Again, we found only $2.02 \%$ of the foramina to be directed anteriorly, a figure that is much lower than that documented by Chrcanovic and Custódio $(69.38 \%),{ }^{(14)}$ and Wang et al $(90.5 \%) .{ }^{(12)}$ The occurrence of an anterolaterally directed foramen is of clinical significance, as it is difficult to negotiate such a foramen with a needle. An anterolaterally directed foramen was seen in only $3.54 \%$ of the skulls in our study, although its incidence in a study of Nigerian skulls by Ajmani was significant at $38.7 \%{ }^{\left({ }^{(8)}\right.}$

The number of LPF ranged between 0 and 5 in the present study, with an average of 1.39 and 1.43 on the right and left sides, respectively. The corresponding findings of Saralaya and Nayak were slightly higher at 1.8 and 1.9 , respectively. ${ }^{(11)}$ In our study, the LPF was bilaterally absent in two skulls and unilaterally absent in 12 skulls (right side $n=5$; left side $n=7$ ). Such absence has previously been reported, but with far lower frequency Saralaya and Nayak found the foramen to be absent in two skulls unilaterally on the left side. ${ }^{(11)}$

A bony lingular projection along the posterior edge of the GPF may be present and would provide a barrier of sorts to the advancing needle as it approaches the GPC to pass into the canal. This would reduce the clinical hazards associated with such injections. Such an anatomic feature has been variably seen in $16 \%{ }^{(9)} 24.6 \%,{ }^{(8)} 27.7 \%$ (present study), $34.5 \%{ }^{(17)}$ and $35.3 \%{ }^{(8)}$ of the skulls studied by various authors.

The patency of the GPC may decrease with age. ${ }^{(8)}$ Hawkins and Isen stated that the difficulty in negotiating the canal may be due to its tortuosity, as seen in 5\% of the population, or due to bony exostosis on the anterior pterygoid plate that comprises the posterior border of the canal.(1) Patency of the GPC was high in our study (95.96\% were patent to a 26 -gauge needle) as well as in the study by Malamed and Trieger $(97.55 \%$ were patent to a 25 -gauge needle). ${ }^{(10)}$ Therefore, it should not pose as a threat to the clinician or be a possible reason for the inability to negotiate the canal.

When using the GPC approach for a maxillary nerve block, it is important to have knowledge of the length of the canal. While unusually long canals could lead to a lack of anaesthesia, short canals could be hazardous due to over-penetration, which might result in an intraorbital or intracranial injection. The distance from the IOF to the alveolar crest between the maxillary bicuspids corresponds well with the length of the canal. ${ }^{(1,10)}$ For patients in whom a subjective assessment reveals an unusually long or short face, this distance can be measured and the value used to gauge the depth of the canal and the extent of needle penetration that could be safely allowed. The mean value of this measurement found in our study was $29.22 \pm 3.21 \mathrm{~mm}$ (range 20.9-37.66 mm), which was considerably lower than that noted by Malamed and Trieger (mean $32.157 \mathrm{~mm}$, range $24-41 \mathrm{~mm}){ }^{(10)}$ Hawkins and Isen found that the length of the canal could be between $24-44 \mathrm{~mm}$, with most adult measurements falling into the $25-30 \mathrm{~mm}$ range. ${ }^{(1)}$ Meanwhile, Bharadwaj and Novotny have advocated the safe extent of penetration to be in the range of $22-25 \mathrm{~mm} .{ }^{(18)}$ Taking into account the inconsistency in values noted by various authors, which could possibly be due to the multiethnic origin of the various skull samples studied, we suggest that when in doubt, it would be worthwhile to measure the actual distance from the IOF to the alveolar crest between the maxillary bicuspids of the patient and use this to gauge the length of the canal.

The anteroposterior (greatest) dimension of the GPF in our study $(4.72 \pm 1.4 \mathrm{~mm})$ correlated well with that recorded by Methathrathip et al $(4.9 \pm 0.9 \mathrm{~mm}){ }^{(6)}$ Aberrations regarding the GPF have been infrequently reported. For instance, Saralaya and Nayak found the dimension of the GPF doubled in a skull. ${ }^{(11)}$ In the present study, complete bilateral absence of both the GPF and LPF was noted in one skull. The other associated anomalies observed in the same skull included the absence of the vomerovaginal and palatovaginal canals, complete obliteration of the pterygomaxillary fissures due to fusion of the pterygoid plates with the body of the maxilla, and bilateral absence of the carotid canals (Figs. 2 \& 3). Distinct grooves along the lateral edges of the hard palate, indicative of the normal position of the greater palatine neurovascular bundle, were present.

Progressive stenosis and subsequent obliteration of the cranial foramina have been reported in craniodiaphyseal dysplasia, which is a rare, severe and progressive bone disorder. It is characterised by the creation of abnormally dense and overgrown bones, resulting in thickening, distortion and enlargement of the cranium and face. ${ }^{(19,20)}$ The skull and mandible of patients suffering from this syndrome show impressive thickening. The entire skull has a roughened surface covered with flat excrescences or exostoses, and the sutures are obliterated due to new bone formation. ${ }^{(20)}$ Keeping in mind the obvious characteristics of such skulls, it was evident that the anomalous skull noted in the present study does not fit into the category of this syndrome. Moreover, apart from the bilateral absence of the GPF, the only other major foramina found to be absent were those for the carotid canals. The remaining foramina were completely normal in terms of their presence, shape and dimension. Since the skull was an adult one (indicated by the presence of erupted third molars), it was 
inconceivable that any pathological process of sclerosing bone dysplasia, beginning in the early years of life, would be allowed to progress to such an extent as to completely eradicate the carotid canals without causing fatality long before such a state was reached. The foraminal aberrations noted in this skull were thus, in all probability, not a consequence of a postnatal progressive pathology, but more likely a manifestation of an intrauterine maldevelopment process affecting the skull base, which continued to be present in the perinatal period. Judging by the age of the skull, the anomalies were compatible with life.

Abnormalities in the palatal foramen and vessel distribution have been noted in several anatomic dissections of patients with Treacher Collins syndrome. ${ }^{(21-23)}$ McKenzie and Craig, for instance, found that the maxillary artery terminated prior to reaching the pterygomaxillary fissure after it had supplied the inferior alveolar, posterior superior alveolar and middle meningeal arteries. ${ }^{(21)}$ The palatal supply in this case was by the posterior superior alveolar vessels and the infraorbital artery, which is a branch of the ophthalmic artery. Herring et al, who dissected the cadaver of a seven-year-old boy diagnosed with Treacher Collins syndrome, ${ }^{(23)}$ found that the IOF was absent and the infraorbital neurovascular bundle was distributed instead to the palate. They also found that the sphenopalatine artery entered the palate via a foramen near the pterygoid hamulus and an anomalous vessel representing the greater palatine artery entered the hard palate through a foramen $9 \mathrm{~mm}$ anterior to the GPF. ${ }^{(23)}$ The major features of Treacher Collins syndrome include deficient zygomatic-temporal bone formation, apart from other bony features such as a kyphotic skull base, stenosed or absent external auditory meati and palatine bones incompletely formed along their midline union. ${ }^{(22)}$ Since none of these features were present, we could not classify the anomalous skull with the absent palatine foramina in our study as having belonged to a patient with Treacher Collins syndrome.

Developmentally, the maxilla is assembled from six cell populations of the 2 neural crest, all of which sweep forward toward the developing face in a strictly spatiotemporal order according to their site of origin. ${ }^{(24)}$ Each population gains its blood supply from the maxillary artery. The physical anatomy and the order in which these arteries (including the medial and lateral sphenopalatine arteries, the greater palatine artery and the superior alveolar branches of the infraorbital artery) branch off from the parent stem replicate the spatiotemporal order of the fields they serve. ${ }^{(24)}$ The inability of neural crest cells to induce a supportive neurovascular supply would result in anomalies in the functional matrix (mesenchyme) available for the formation of a given field, translating into the genesis of various types of craniofacial clefts. ${ }^{(25)}$ Therefore, the absence of any apparent bony defect in the maxilla of the anomalous skull in our study indicates undoubtedly the presence of adequate neurovascular supply to this region in critical stages of intrauterine development. Coupled with the fact that both the GPF as well as the LPF were bilaterally absent in this skull, we concluded that the neurovascular supply to the palate might have gained access via an alternative route. Though the embryogenesis of the anomalous absence of the palatine foramina is open to interpretation, we opine that an atypical or aberrant migration of the neural crest cells to have altered the course of the nerves and vessels that would supply that particular population of cells. It is possible that the greater palatine neurovascular bundle had entered the palate via the incisive canals and then passed posteriorly to supply the hard and soft palate. This theory is supported by the presence of grooves along the edges of the hard palate, indicating the presence of such structures. Although we have no way of infallibly proving the above theory, such a possibility, however rare, is worth considering in view of its clinical implications, as a traditional approach by the surgeon when reconstructing the cleft palate in a patient with such an aberrant vascular anatomy would prove disastrous. Oral surgeons too must be aware of such an anomaly when performing maxillary blocks.

In conclusion, we propose that the maxillary molars, pterygoid hamulus and the midline maxillary suture are oral landmarks that may be employed for accurately plotting the GPF. The foramen may be found most frequently palatal to the third maxillary molar, and in cases where this tooth has not erupted, it may be expected to be distal to the second molar. For an edentulous patient, clinicians may expect to locate the foramen 14-15 mm from the midpalatal raphe or about $12 \mathrm{~mm}$ anterior to the palpable pterygoid hamulus. In Indian patients, the relation of the GPF to the posterior palatal border is fairly consistent and the foramen can be found 3-4 mm anterior to it. Generally, the patency of the canal to a 26-gauge needle should not be a problem. However, given the variability in the length of the canal, as indicated by the perpendicular distance from the IOF to the alveolar crest between the maxillary bicuspids, no definite mean value can be prescribed for this measurement. Keeping in mind the hazards of both over- and under-penetration of the needle, we suggest that the surgeon should not hesitate to measure the distance to ensure no impediments to subsequent procedures. Finally, however rare, one must remain cognizant of the possibility of an aberrant neurovascular supply to the palate - even in an overtly normal, non-syndromic patient - and the clinical implications of such an anatomy while working on an individual.

\section{ACKNOWLEDGEMENT}

We would like to extend our gratitude to Dr SB Muley, MSc, PhD (Statistics), Associate Professor, KC College, Mumbai, India.

\section{REFERENCES}

1. Hawkins JM, Isen D. Maxillary nerve block: the pterygopalitine canal approach. J Calif Dent Assoc 1998; 26:658-64.

2. Standring S, Ellis H, Healy JC, et al, eds. Oral cavity. In: Gray's Anatomy: The Anatomical Basis of Clinical Practice. 39th Ed. London: Elsevier, Churchill Livingstone, 2005: 584.

3. Blanton $\mathrm{PL}$, Jeske AH. The key to profound local anesthesia: neuroanatomy. J Am Dent Assoc 2003; 134:753-60.

4. Langford RJ. The contribution of the nasopalatine nerve to sensation of the hard palate. Br J Oral Maxillofac Surg 1989; 27:379-86.

5. Howard-Swirzinski K, Edwards PC, Saini TS, Norton NS. Length and 
geometric patterns of the greater palatine canal observed in cone beam computed tomography. Int J Dent 2010; pii: 292753.

6. Methathrathip D, Apinhasmit W, Chompoopong S, et al. Anatomy of greater palatine foramen and canal and pterygopalatine fossa in Thais: considerations for maxillary nerve block. Surg Radiol Anat 2005; 27:511-6.

7. Malamed SF. Handbook of Local Anesthesia. 5th ed. St. Louis: Elsevier Mosby, 2004.

8. Ajmani ML. Anatomical variation in position of the greater palatine foramen in the adult human skull. J Anat 1994; 184:635-7.

9. Westmoreland EE, Blanton PL. An analysis of the variations in position of the greater palatine foramen in the adult human skull. Anat Rec 1982; 204:383-8.

10. Malamed SF, Trieger N. Intraoral maxillary nerve block: an anatomical and clinical study. Anesth Prog 1983; 30:44-8.

11. Saralaya $V$, Nayak SR. The relative position of the greater palatine foramen in dry Indian skulls. Singapore Med J 2007; 48:1143-6.

12. Wang TM, Kuo KJ, Shih C, Ho LL, Liu JC. Assessment of the relative locations of the greater palatine foramen in adult Chinese skulls. Acta Anat (Basel) 1988; 132:182-6.

13. Klosek SK, Rungruang T. Anatomical study of the greater palatine artery and related structures of the palatal vault: considerations for palate as the sub epithelial connective tissue graft donor site. Surg Radiol Anat 2009; 31:245-50.

14. Chrcanovic BR, Custódio AL. Anatomical variation in the position of the greater palatine foramen. J Oral Sci 2010; 52:109-13.

15. Sujatha N, Manjunath KY, Balasubramanyam V. Variations of the location of the greater palatine foramina in dry human skulls. Indian J Dent Res
2005; 16:99-102

16. Hassanali J, Mwaniki D. Palatal analysis and osteology of the hard palate of the Kenyan African skulls. Anat Rec 1984; 209:273-80.

17. Aterkar S, Rawal PM, Kumar P. Position of greater palatine foramen in adults. J Anat Soc India 1995; 44:126-33.

18. Bharadwaj VK, Novotny GM. Greater palatine canal injection: an alternative to the posterior nasal packing and arterial ligation in epistaxis. J Otolaryngol 1986; 15:94-100.

19. McHugh DA, Rose GE, Garner A. Nasolacrimal obstruction and facial bone histopathology in craniodiaphyseal dysplasia. Br J Ophthalmol 1994 78:501-3.

20. Van Hul W, Balemans W, Van Hul E, et al. Van Buchem disease (hyperostosis corticalis generalisata) maps to chromosome 17q12-q21. Am J Hum Genet 1998; 62:391-9.

21. McKenzie J, Craig J. Mandibulo-facial dysostosis (Treacher Collins syndrome) Arch Dis Child 1955; 30:391-5.

22. Behrents RG, McNamara JA, Avery JK. Prenatal mandibulofacial dysostosis (Treacher Collins syndrome). Cleft Palate J 1977; 14:13-34.

23. Herring SW, Rowlatt UF, Pruzansky S. Anatomical abnormalities in mandibulofacial dysostosis. Am J Med Genet 1979; 3:225-9.

24. Carstens $\mathrm{MH}$. Neural tube programming and the pathogenesis of craniofacial clefts. Part II: mesenchyme, pharyngeal arches, developmental fields; and the assembly of the human face. In: Sarnat HB, Curatolo P, eds. Handbook of Clinical Neurology. London: Elsevier, 2008: chapter 17.

25. Ewings EL, Carstens MH. Neuroembryology and functional anatomy of craniofacial clefts. Indian J Plast Surg 2009; 42:19-34.

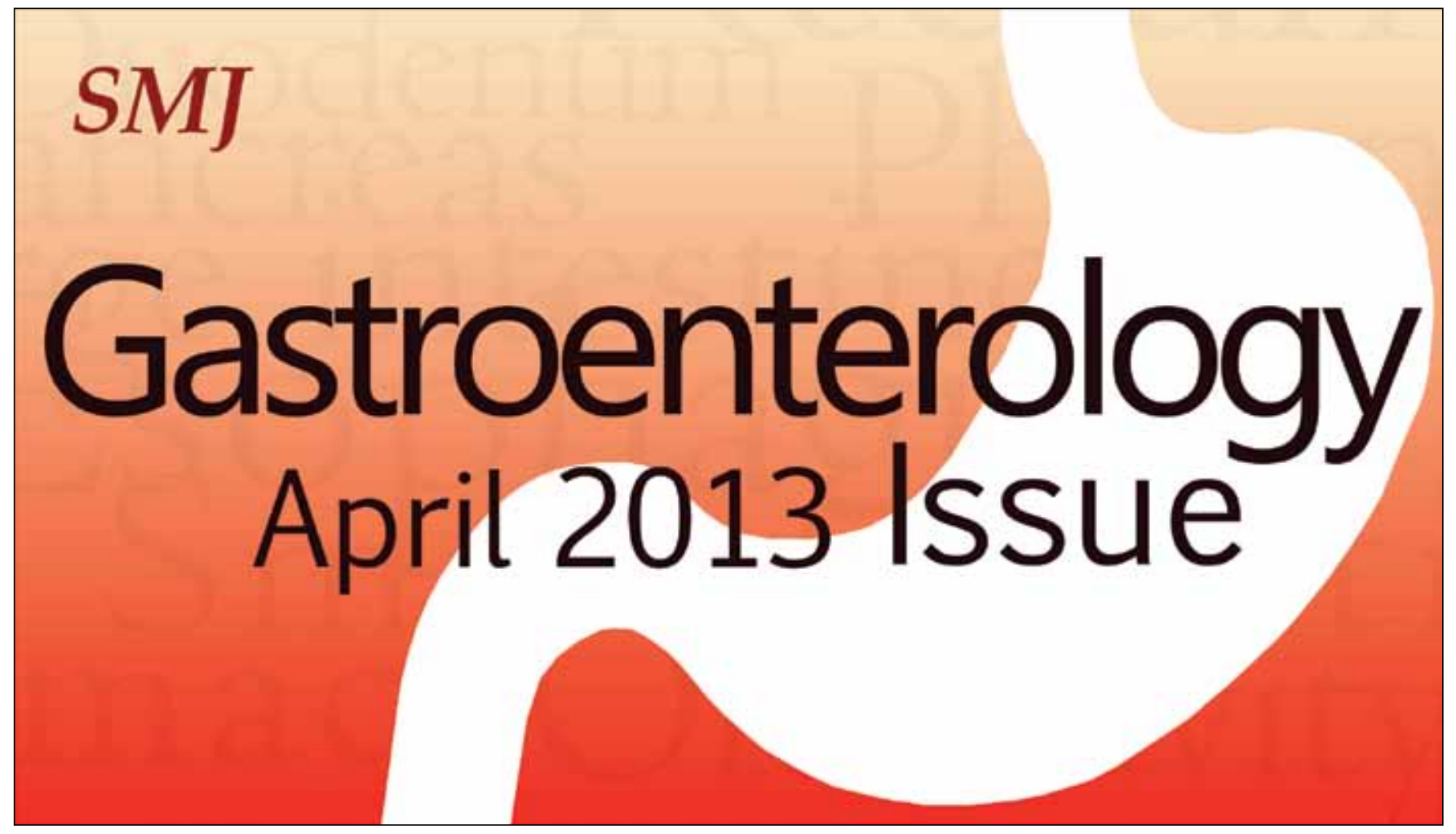

